\title{
¿Linfoma de Hodking?
}

\author{
¿Hodking lymphoma?
}

Alfredo Pinzón • Bogotá, D.C. (Colombia)

\section{¿Linfoma de HodkING?}

Ocasionalmente se encuentra el uso incorrecto del epónimo Linfoma de Hodking. Este tipo de cáncer del tejido linfoide fue llamado así en honor al médico inglés Thomas Hodgkin, quien junto con Richard Bright y Thomas Addison introdujo el pensamiento anatomo-clínico en Inglaterra.

Hodgkin nació en Pentoville, cerca de Londres, y estudió medicina en los hospitales St. Guy y St. Thomas, pero en 1819 se trasladó a la Universidad de Edimburgo. Luego completó su formación en el Hospital Necker de París con René Laennec, de quien aprendió el uso del estetoscopio; a su regreso presentó su trabajo sobre este nuevo instrumento en la Guy's Hospital Physical Society y se le atribuye la introducción de este instrumento en Londres.

En 1825 fue nombrado lecturer de "anatomía morbosa" y curator (conservador) del Museo de Patología de la Escuela de Medicina del Hospital St. Guy, lo que le dio la oportunidad de realizar más de 100 necropsias por año y formarse en anatomía patológica. En 1832 publicó “On Some Morbid Appearances of the Absorbent Glands and Spleen”, en donde describió siete casos de esplenomegalia y adenopatías que había estudiado; relacionó los nódulos linfáticos con el bazo por su semejanza macroscópica. En 1838 Bright señaló que esa descripción definía una nueva enfermedad, y en 1856 Samuel Wilks, quien también fue conservador del Museo como Hodgkin, publicó una serie de 45 casos que incluían los de éste, y acuñó el término "Enfermedad de Hodgkin".

Thomas Hodgkin también fue uno de los primeros en describir la insuficiencia aórtica; promovió temas de salud pública y se preocupó por la enseñanza de la medicina. Además, participó en la reforma social y humanitaria de su época, luchando por el empleo, vivienda digna y asistencia médica para los más pobres. También hizo aportes en antropología, política, colonización y abolición de la esclavitud.

La forma correcta del epónimo (respetando la grafía original del apellido en la que la $\mathrm{G}$ antecede a la K) es:

\section{Enfermedad de HodGKIN*}

* En español también es aceptable la expresión Linfoma de Hodgkin

\section{Fuentes:}

- www.historiadelamedicina.org

- Stone MJ. Thomas Hodgkin: medical immortal and uncompromising idealist. Proc Bayl Univ Med Cent 2005; 18(4): 368-75

- Real Academia Nacional de Medicina. Diccionario de Términos Médicos. Editorial Médica Panamericana. 2012.

- U.S. National Library of Medicine, disponible en: www.ncbi.nlm.nih.gov

* Envíe sus inquietudes, sugerencias o comentarios a: actmedco@etb.net.co - alfredo.pinzon@hus.org.co Dr. Alfredo Pinzón Junca: Especialista en Medicina Interna y Psicoanálisis. Hospital Universitario de La Samaritana y Hospital Simón Bolívar. Comité de Educación y Comunicaciones de la ACMI®. Bogotá, D.C. (Colombia).

E-mail: alfredo.pinzon@hus.org.co

Recibido: 19/XI/2012 - Aceptado: 21/XI/2012 